\title{
Variations in melt emplacement beneath the northern East African Rift from radial anisotropy
}

\author{
Emma L. Chambers ${ }^{\mathrm{a}, *, 1}$, Nicholas Harmon ${ }^{\mathrm{a}}$, Catherine A. Rychert ${ }^{\mathrm{a}}$, Derek Keir ${ }^{\mathrm{a}, \mathrm{b}}$ \\ a University of Southampton, Southampton, UK \\ b Dipartimento di Scienze della Terra, Università degli Studi di Firenze, Florence, Italy
}

\section{A R T I C L E I N F O}

\section{Article history:}

Received 23 December 2020

Received in revised form 29 July 2021

Accepted 5 August 2021

Available online 1 September 2021

Editor: H. Thybo

\section{Keywords:}

surface waves

tomography

radial anisotropy

East African Rift

ambient noise

Rayleigh and Love waves

\begin{abstract}
A B S T R A C T
Where and how melt is stored in the crust and uppermost mantle is important for understanding the dynamics of magmatic plumbing systems and the evolution of rifting. We determine shear velocity and radial anisotropy in the magmatically rifting northern East African Rift to determine the locus and orientation of melt, both on and off-rift. Love and Rayleigh fundamental modes are extracted from ambient noise data from 9-26 s period and then inverted for shear velocity. $V_{S V}$ is $0.15 \pm 0.03 \mathrm{~km} / \mathrm{s}$ lower than $V_{S H}$ from 5-30 km depth on average. $V_{S H}>V_{S V}$ across most of the study region suggests the crust is inherently horizontally layered, with the largest anisotropy in the upper 5-15 km. Effective medium theory suggests thin compositional layering of felsic and mafic intrusions can account for anisotropy up to $4 \%$. However, to reconcile the largest observed anisotropy (6.5\%), and lowest velocities, we require $2-4 \%$ partial melt oriented in sills. Along the rift, horizontally aligned radial anisotropy gets weaker north-eastwards, suggesting sills become less dominant with progressive rifting. The Erta Ale magmatic segment is the only location where $\mathrm{V}_{\mathrm{SV}}>\mathrm{V}_{\mathrm{SH}}$, suggesting the crust contains vertical micro-cracks and dykes. Overall, the results suggest during early continental breakup when the rift is narrow, sill formation is the dominant storage mechanism. As a rift widens, vertical dyke intrusion becomes dominant and is likely controlled by variations in crustal thickness and stress state.
\end{abstract}

(c) 2021 Elsevier B.V. All rights reserved.

\section{Introduction}

During rifting, the crust is thinned and faulted to accommodate extension; however, in magmatic rift systems there may be significant crustal addition due to intrusive and extrusive magmatism (Thybo and Nielsen, 2009). Where and how magma is stored in the crust has important implications for its strength, as the presence of partial melt and heat causes crustal weakening (Daniels et al., 2014). The depth of storage is a key factor for magmatic evolution, transforming mafic mantle melts to more felsic compositions. Moreover, the depth of storage, location and geometry of partial melt, present another control on mineralization, important for economic resources. Yet, in many rifts globally, the depths and geometry of magmatic emplacement, both past and present, remains difficult to constrain (Hutchison et al., 2018).

The subaerial northern East African Rift (nEAR) provides a unique opportunity to investigate crustal modification during rifting via magmatic emplacement and volcanism (Wolfenden et al.,

\footnotetext{
* Corresponding author.

E-mail address: echambers@cp.dias.ie (E.L. Chambers).

1 Now at Dublin Institute for Advanced Studies, Dublin, Ireland.
}

2005). Previous geophysical studies have revealed insights into the location of melt and fluids in the crust (e.g. Bastow et al., 2010; Chambers et al., 2019; Hammond, 2014; Whaler and Hautot, 2006), and volcanoes and their eruptive outputs, provide geologic information at the surface. Recent surface geology, geophysical and geodetic studies have reported melt beneath the Main Ethiopian Rift (MER) at mid-to-lower crustal depths and as shallow magma chambers located at $\sim 5 \mathrm{~km}$ depth beneath the magmatic segments (Chambers et al., 2019; Whaler and Hautot, 2006). Within Afar, high $V_{p} / V_{s}$ ratios (>2.1) (Hammond et al., 2011) suggest melt is present at crustal depths. InSAR studies provide further evidence for the migration and storage of melt in the upper crust (Moore et al., 2019). Off-rift beneath the Ethiopian Plateau, melt has been imaged within the mid-to-lower crust (Chambers et al., 2019; Maguire et al., 2006; Whaler and Hautot, 2006), as far north as Lake Tana (Chambers et al., in review; Whaler and Hautot, 2006).

Seismic anisotropy can provide additional insight into the shape and structure of magmatic systems, with Shape Preferred Orientation (SPO) generated by planar features such as faults, sills and dykes, with velocities substantially different from the country rock (Kendall et al., 2006). Previous studies of anisotropy within the nEAR, found evidence for melt beneath the rifts and the Ethiopian 
Plateau at mantle and crustal depths (Bastow et al., 2010; Hammond et al., 2014; Keir et al., 2011; Kendall et al., 2006). At asthenospheric depths, anisotropy is primarily controlled by olivine alignment. However, at the base of the mantle lithosphere, oriented melt pockets become increasingly important in controlling anisotropy (Bastow et al., 2010; Hammond et al., 2014; Kendall et al., 2006). At lower crustal depths, anisotropic H- $\kappa$ stacking of receiver functions (Hammond, 2014) and surface waves (Bastow et al., 2010), found evidence for melt stored in stacked sills beneath Afar, the MER and the off-rift Ethiopian Plateau. Local earthquake splitting and $\mathrm{H}-\kappa$ stacking of receiver functions results suggest sills in the rift, particularly within Afar, connect to the upper crust through a series of dykes and aligned fracture networks (Hammond, 2014; Keir et al., 2011). In contrast, surface wave anisotropy found evidence for $V_{S H}>V_{S V}$ consistent with strong layering in the upper $10 \mathrm{~km}$ of crust in the MER (Bastow et al., 2010). While these studies provide insight into melt storage at crustal depths, the models focus on small regions with differing methods that are not directly comparable, further complicating our knowledge on how melt is stored and whether magma reservoir geometry changes through rift evolution.

Rifting within the nEAR initiated $\sim 30 \mathrm{Ma}$, just after the emplacement of the Ethiopian flood basalt province (Wolfenden et al., 2005). The rift is comprised of 3 arms: the Red Sea rift, Gulf of Aden rift and the MER. Rifting in Afar, the Gulf of Aden and Red Sea initiated 29-26 Ma while the MER started rifting 20 Ma in the south, with the central and northern sections rifting 18 and $11 \mathrm{Ma}$, respectively (Fig. 1a) (Wolfenden et al., 2005). Within the Afar depression, the $16-25 \mathrm{~km}$ thick crust is highly intruded compared to the $35-45 \mathrm{~km}$ thick crust of the Ethiopian Plateau and MER (Hammond et al., 2011; Maguire et al., 2006; Ogden et al., 2019). Quaternary-recent volcanism has focussed to the magmatic segments within the rift, with little evidence for present-day volcanism on the Ethiopian Plateau (Wolfenden et al., 2005) while Geothermal activity, is present both on and off-rift (Keir et al., 2009).

Here, we present a new high resolution radially anisotropic shear velocity model for the nEAR crust, from ambient noise crosscorrelation functions. This work builds on Rayleigh wave ambient noise tomography studies in Chambers et al. (2019) and Chambers et al. (in review), by incorporating Love waves for radial anisotropy. Chambers et al. (2019) found uppermost mantle velocities low enough to contain 1.1-2\% melt, while heterogeneous velocities beneath the Ethiopian Plateau suggested a complex evolution process. Chambers et al. (in review) added data for the Ethiopian Plateau and jointly inverted with teleseismic surface waves, finding evidence for ongoing magmatic emplacement beneath the Ethiopian Plateau and segmented low velocity bodies in the asthenosphere beneath the MER, offset from melt-rich crustal regions. Our new model allows us to interpret variations in crustal structure from compositional layering, alignment of microcracks and the presence of fluids, and use this to infer past and present emplacement of melt within the crust of an active rifting system.

\section{Methods}

\subsection{Datasets and pre-processing}

We used data recorded by continuous 3-component broadband seismometers from 13 temporary networks and 5 permanent stations present at varying intervals between 1999-2017 (Fig. 1a). The stations are the same as Chambers et al. (in review) but include the north-south, east-west components, in addition to the vertical component. We do not use the RiftVolc network due to short station separation. Furthermore, networks and stations with short deployment durations were not included. The data were

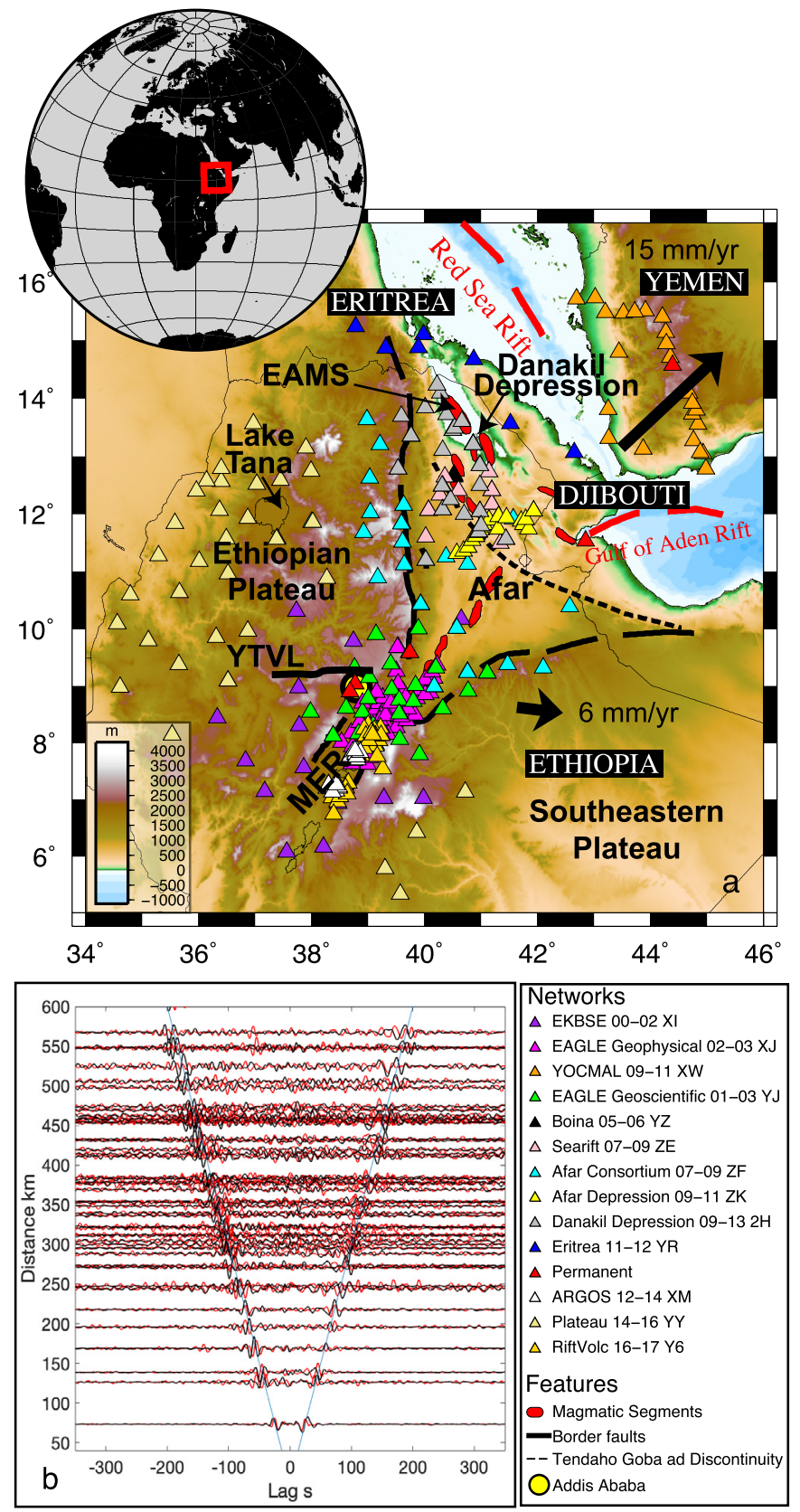

Fig. 1. (a) Seismic Station map of the northern East African Rift. Thick black lines show border faults, red polygons magmatic segments, and dashed lines the Tendaho-Goba'ad discontinuity (TGD). Stations are triangles coloured to their project deployment. Addis Ababa is marked by yellow circle. The Erta Ale Magmatic Segment (EAMS) in red is indicated with an arrow and YTVL is the Yerer Tullu Wellel Volcanotectonic lineament. (b) NCF for transverse-transverse components (red) and vertical-vertical components (black). Ray paths for the NCF shown in Fig. 2a. (For interpretation of the colours in the figure(s), the reader is referred to the web version of this article.)

downsampled to $1 \mathrm{~Hz}$, normalised, and whitened with a $4^{\text {th }}$ order Butterworth bandpass filter of $0.005-0.4 \mathrm{~Hz}$ following the method of Bensen et al. (2007). 24-hour long waveforms were cross-correlated for each concurrent running station pair between the vertical components $\left(C_{z z}\right)$ and all combinations of correlations between the north and east components before rotating into the transverse $\left(C_{\mathrm{tt}}\right)$ and radial components $\left(C_{\mathrm{rr}}\right)$ (Lin et al., 2008). The cross-correlograms were stacked for each station pair for every day to improve the signal to noise ratio (SNR) (Fig. 1b). We tested the long-term stack against 30 day stacks and verified that phase ar- 

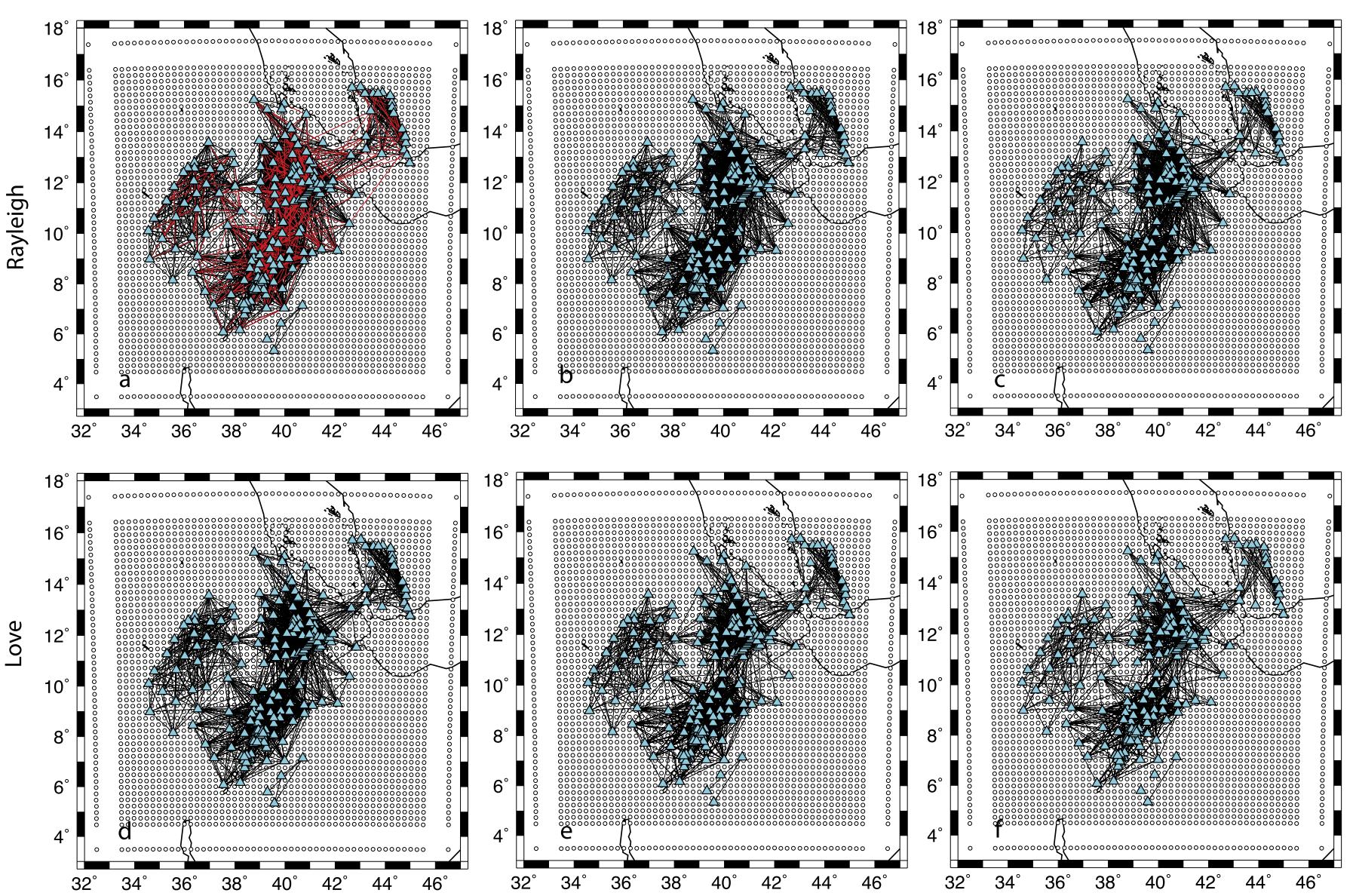

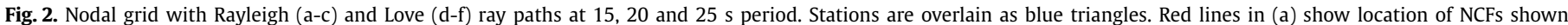
in Fig. 1.

rival times were consistent, within 1-2 s (Bensen et al., 2007). Station pairs with interstation distances less than $3 \times$ wavelength $(\lambda)$ or had less than 10 days' worth of continuous recording were removed, which we considered unstable. We also required SNR $>3$ at any given period, resulting in 6716 NCF for Rayleigh (Chambers et al., in review) and 2860 for Love. Finally, the fundamental mode Rayleigh and Love wave data were windowed using a time variable filter (Landisman et al., 1969), and the Fourier amplitude and phase calculated at each frequency of interest via a fast Fourier transform.

\subsection{Phase velocity}

Phase velocity dispersion curves for each station pair were estimated using a spatial domain technique. A zero order Bessel function of the first kind was fitted to the real part of the NCF in the Fourier domain by searching over phase velocities from 2.5-5 $\mathrm{km} / \mathrm{s}$ in $0.01 \mathrm{~km} / \mathrm{s}$ steps for every period of interest with an even period distribution. For each stacked NCF the phase was measured at each period by unwrapping the phase using the average phase velocity curve at the longest periods, to resolve cycle ambiguity (Bensen et al., 2007). Phase velocity maps for Rayleigh (verticalto-vertical component) and Love waves (transverse-to-transverse) were produced by inverting the phase using the Born approximation 2-D phase sensitivity kernels (Zhou et al., 2004) and an iterative damped least squares approach (Harmon et al., 2007; Tarantola and Valette, 1982). We used a regular grid of nodes spaced $0.25^{\circ}$ $\times 0.25^{\circ}$ and averaged the sensitivity kernel between each station pair onto the nodes (Harmon and Rychert, 2015; Yang and
Forsyth, 2006) (Fig. 2). The sensitivity kernel was calculated on a densely sampled grid $\left(0.1^{\circ} \times 0.1^{\circ}\right)$ and then the Gaussian distanceweighted average was taken to determine the value at each node on the coarser grid with a Gaussian smoothing width $(2 \sigma)$ of 40 $\mathrm{km}$. We "undo" the Gaussian weighted average after inverting for the average phase velocity to recover a $0.1^{\circ} \times 0.1^{\circ}$ grid by determining the Gaussian weighted contribution of the nearest nodes to each pixel using the same $40 \mathrm{~km}$ Gaussian width. This produced well resolved phase velocities between 9-26 s varying between $\pm 0.02-0.07 \mathrm{~km} / \mathrm{s}$ for both Love and Rayleigh waves (Fig. 3 and Fig. 4). An a priori damping parameter of $0.2 \mathrm{~km} / \mathrm{s}$ was used in the phase velocity inversion to stabilise the inversion but not be restrictive (Forsyth and $\mathrm{Li}, 2005$ ).

\subsection{Shear velocity and radial anisotropy}

The shear velocity inversion was performed by inverting each pixel of the phase velocity maps for a 1-D radially anisotropic shear velocity model at every pixel as a function of depth (Fig. 3). The combined 1-D shear velocities and anisotropy, at each pixel, form the 3-D volumes (Fig. 5). For the anisotropic P and S-velocity structure, five elastic parameters are used:

$\mathrm{A}=\rho \mathrm{V}_{\mathrm{PH}}^{2}, \quad \mathrm{C}=\rho \mathrm{V}_{\mathrm{PV}}^{2}, \quad \mathrm{~L}=\rho \mathrm{V}_{\mathrm{SV}}^{2}, \quad \mathrm{~N}=\rho \mathrm{V}_{\mathrm{SH}}^{2}, \quad$ and $\quad \mathrm{F}$

where $V_{P}$ is compressional velocity and $V_{S}$ is shear velocity (Montagner and Anderson, 1989). Subscript $\mathrm{H}$ and V refer to horizontal and vertical respectively. We use an alternative parameterisation 

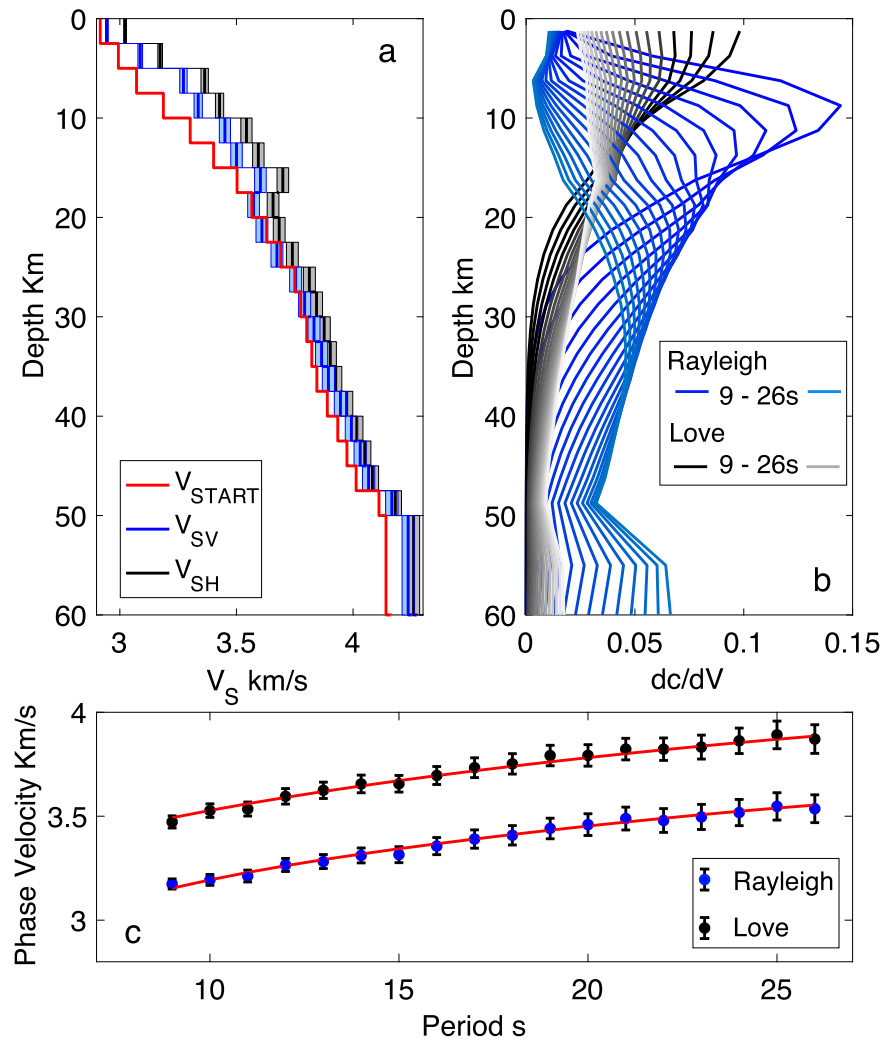

Fig. 3. a) Shear velocity structure for $\beta V$ (blue) and $\beta H$ (black) with $95 \%$ confidence regions, and the starting model (red) taken for the average of the full study area after the initial 1-D inversion. b) Sensitivity kernels for Love (black) and Rayleigh (blue) waves at select periods. c) One dimensional phase velocities for Love (black circles) and Rayleigh (blue circles) waves, with corresponding predicted phase velocity from the best fit shear velocity model in red lines. For further 1D profiles in specific areas see Fig. S1.

for the elastic parameters and use the DISPER80 package to calculate the partial derivatives relating Rayleigh and Love wave phase velocities to these elastic parameters (Saito, 1988):

$\xi=\frac{\mathrm{N}}{\mathrm{L}}$

$\varphi=\frac{\mathrm{C}}{\mathrm{A}}$

$\eta=\frac{\mathrm{F}}{\mathrm{A}-2 \mathrm{~L}}$

$\mathrm{V}_{S V}$

and

$V_{P H}$

Usually only $\mathrm{V}_{\mathrm{SV}}$ and $\xi$ (anisotropy) can be well resolved, so to reduce the number of parameters we scale

$\delta \ln \varphi=-1.5 \delta \ln \delta \mathrm{V}$ and

$\delta \ln \eta=-2.5 \ln \delta \mathrm{V}$

(Montagner and Anderson, 1989). We fix $\mathrm{V}_{\mathrm{PH}} / \mathrm{V}_{\mathrm{SV}}=1.80$ which is the crustal average from receiver function analyses (e.g. Hammond et al., 2011). Variations in $\mathrm{V}_{\mathrm{PH}} / \mathrm{V}_{\mathrm{SV}}(1.5-2.1$, the observed $\mathrm{Vp} / \mathrm{Vs}$ ratios in this area), and scaling parameters, produce results within error and we present the formal error from the inversion in Fig. 3.

For the shear velocity inversion, we parameterised the model every $2.5 \mathrm{~km}$ vertically, with a $0.1^{\circ} \times 0.1^{\circ}$ pixel size, and used a damped least squares approach (Tarantola and Valette, 1982). We calculated the partial derivatives that relate variations in shear velocity $\left(\mathrm{V}_{\mathrm{SV}}\right.$ and $\left.\mathrm{V}_{\mathrm{SH}}\right)$ to changes in phase velocity using DISPER80 (Saito, 1988) and assigned a nominal a priori standard error for each model parameter of $0.2 \mathrm{~km} / \mathrm{s}$ for shear velocity and 0.1 for $\xi$. The resulting 3-D velocity structure is shown from 5-30 km depth (Fig. 5). The shear velocity model has been interpolated to $1 \mathrm{~km}$ depth using a linear interpolation (originally $2.5 \mathrm{~km}$ ), for presentation purposes (Fig. 3).

We present our results for anisotropy $(\delta \mathrm{V})$, as a percentage in terms of

$\delta \mathrm{V}=100 *\left(\frac{\mathrm{V}_{\mathrm{SH}}}{\mathrm{V}_{\mathrm{SV}}}-1\right)$

where $\sqrt{\xi}=\frac{V_{S H}}{V_{S V}}$. Values $>0\left(V_{S H}>V_{S V}\right)$ indicate horizontally aligned radial anisotropy, whereas values $<0 \quad\left(\mathrm{~V}_{\mathrm{SH}}<\mathrm{V}_{\mathrm{SV}}\right)$ indicate regions of vertically aligned anisotropy. The depth sensitivity for both Rayleigh and Love waves at this frequency range are broad, making precise determination of depth difficult. Furthermore, anisotropy is significant from $5-30 \mathrm{~km}$ (Fig. 3a). Therefore we only interpret anisotropy in this range. We present depth averages of radial anisotropy (5-15 km and 16-30 km depth, Fig. 5), where the formal resolution matrix of the linearized damped least squares inversion indicates a well resolved average. We acknowledge there may be some trade-off in the absolute depth of the anisotropy. Sensitivity tests indicate we can image and interpret radial shear velocity from 5-40 km depth (Fig. 3b), however we present the shear velocity models similarly to the radial anisotropy to allow direct comparison.

\subsection{Errors and resolution}

Checkerboard tests were produced for both Love and Rayleigh phase velocities, with lateral anomaly sizes of $0.64^{\circ}(70 \mathrm{~km}), 1^{\circ}$ and $1.5^{\circ}$ length scales (Fig. 6). For the Rayleigh phase velocities, anomalies are well recovered in the rift and off-rift towards Lake Tana at $0.64^{\circ}$ length scale, for all periods used in this study (9$26 \mathrm{~s}$ ). Whereas for Love phase velocities, anomalies are reasonably well recovered from 9-20 $\mathrm{s}$ in the rift, and only at the shortest periods off-rift. At $1^{\circ}$ length scales, Rayleigh phase velocity checkers are well resolved for every period. In contrast, $1^{\circ}$ length scales for Love phase velocities are resolved for 21-26 s in the rift, and resolved everywhere within the $2 \sigma$ error contour from the phase velocity inversion at $1.5^{\circ}$ length scales (Fig. 6). Results outside the $2 \sigma$ standard error contour, from the linearised phase velocity inversion, are masked. We present the formal resolution maps in Fig. S3 for Love and Rayleigh which are derived from the formal resolution matrix. The error is estimated by propagating the error from the nodal parameterisation using the Gaussian weights of each node to each pixel using the full covariance matrix. The values are presented from $0-1$ with 1 indicating the model is fully resolvable with 1 node, and a value of 0.33 would require 3 adjacent nodes to resolve 1 piece of independent information. For the shear velocity model, we propagate the errors from the phase velocity though the inversion, and present the formal error of the linearized damped least squares inversion at the last iteration.

Synthetic recovery tests were generated by adding a low velocity anomaly of similar magnitude to our output model beneath the MER and Ethiopian Plateau (Fig. S2). The results indicate that anomalies in the rift are resolvable at all periods within our model, however those off-rift are resolvable up to $17 \mathrm{~s}$ (Fig. S2). Within the Red Sea and Gulf of Aden Rifts, the results suggest there is smearing at longer periods.

To assess vertical resolution we performed a spike test, which shows the recovery of a spike function input at varying depths 

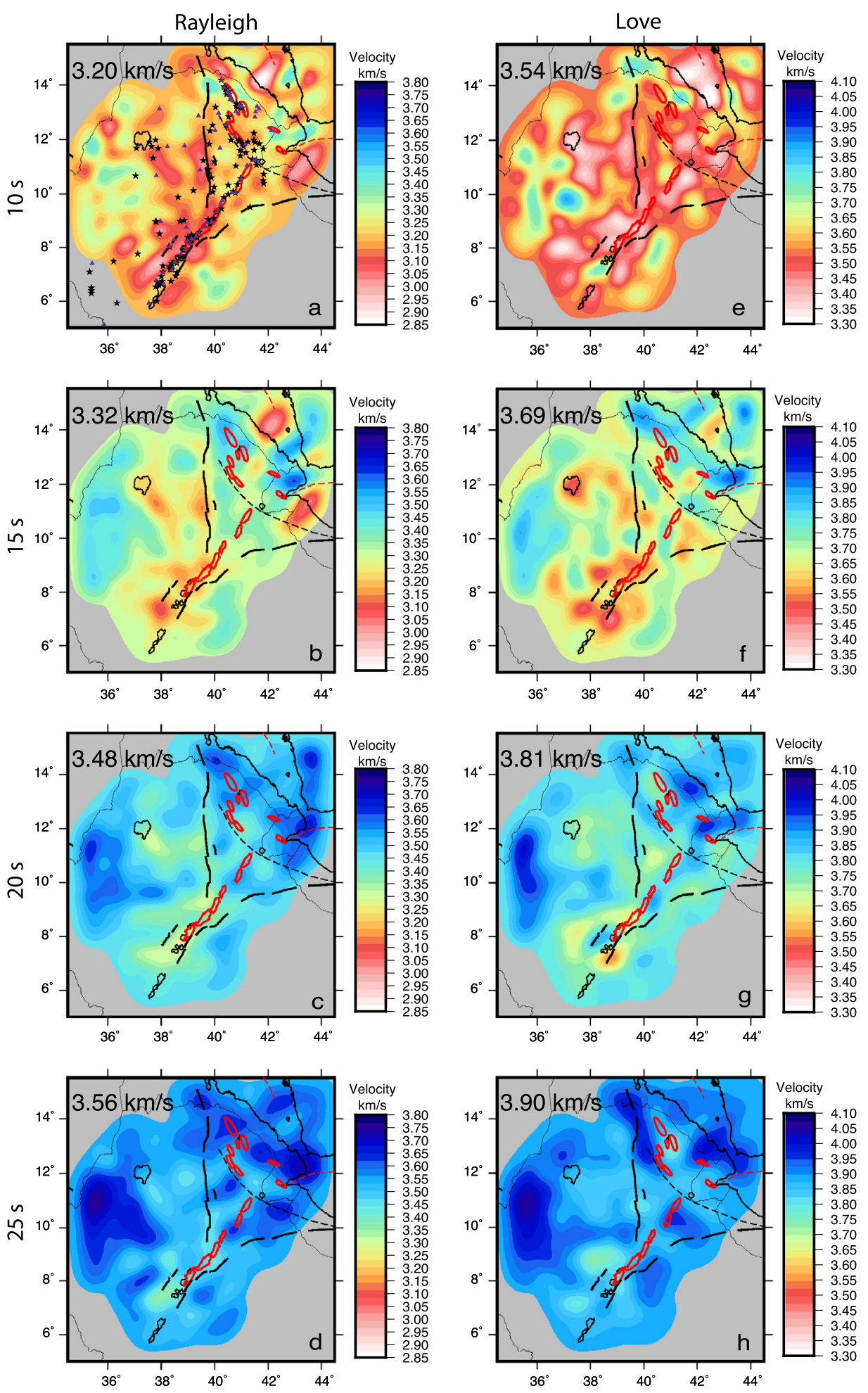

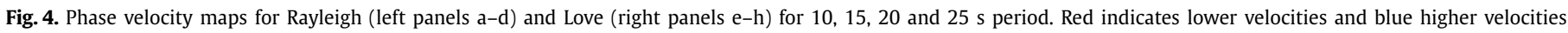

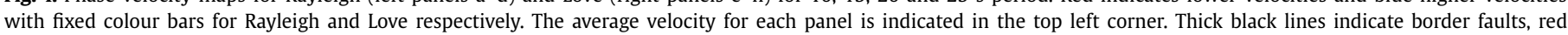
polygons magmatic segments, dashed lines the Tendaho-Goba'ad discontinuity, purple triangles volcanoes, and black stars geothermal activity.

of the formal resolution matrix (Fig. 7). The values are again presented from $0-1$. The kernels suggest shear velocities are resolvable up to $50 \mathrm{~km}$ depth and vertical resolution decreases with increasing depth. At the shallowest depths $(5-22 \mathrm{~km})$ the depth slices are averaged over $\pm 10 \mathrm{~km}$ and from $23-50 \mathrm{~km}$ depth averaged over \pm 15 km (Fig. 7).

\subsection{Effective medium calculations - thin compositional layers}

To identify and interpret the dominant causes of radial anisotropy $\left(\mathrm{V}_{\mathrm{SH}}>\mathrm{V}_{\mathrm{SV}}\right)$ we model the simplest example of horizontal anisotropic structure as transversely isotropic layers with a vertical axis of symmetry (Backus, 1962). We explore whether al- 

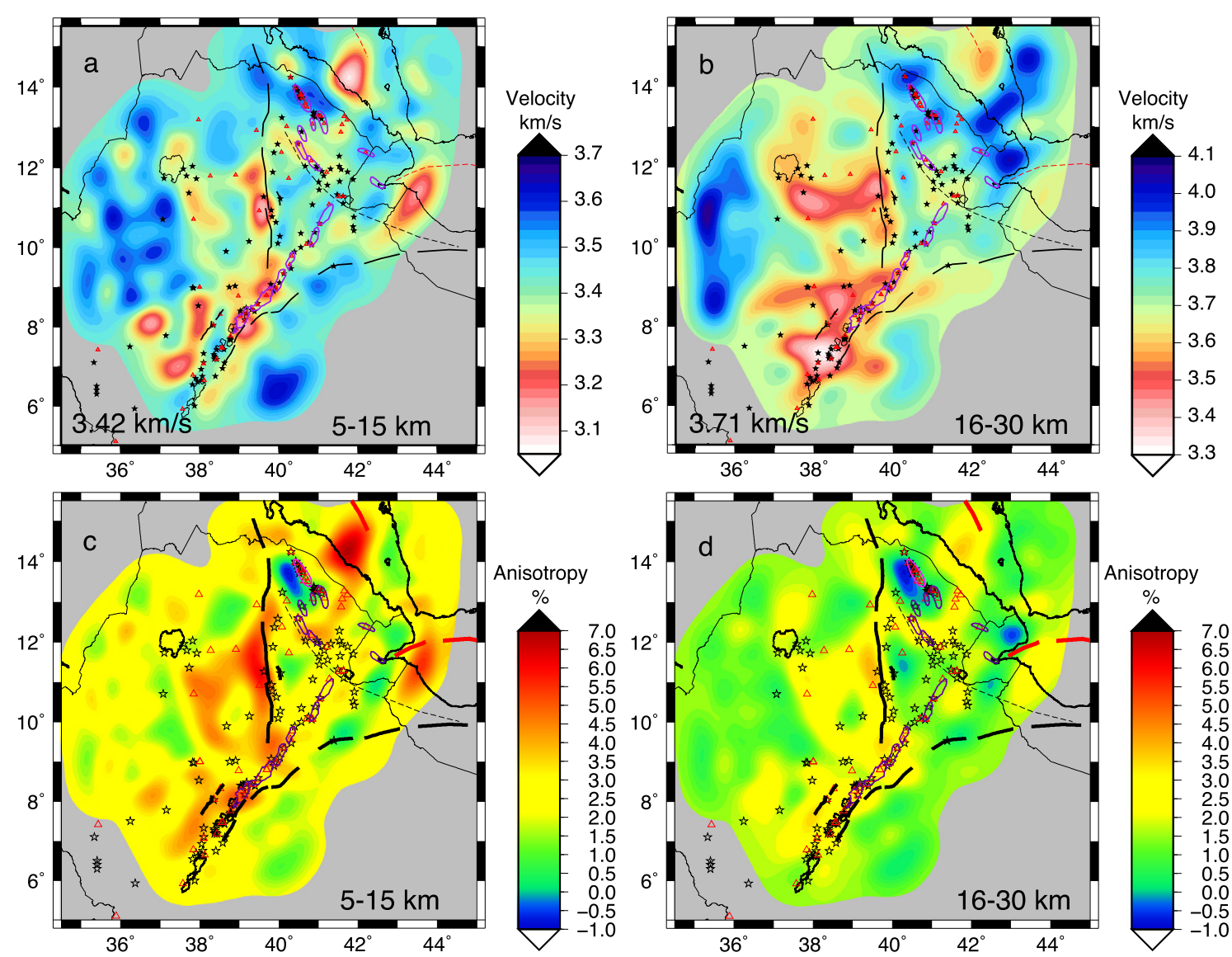

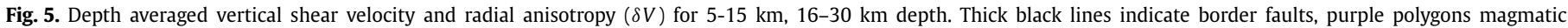

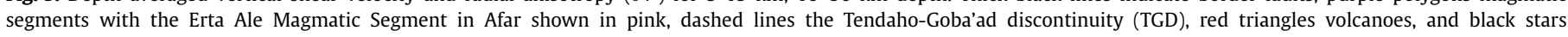
geothermal activity.

Rayleigh
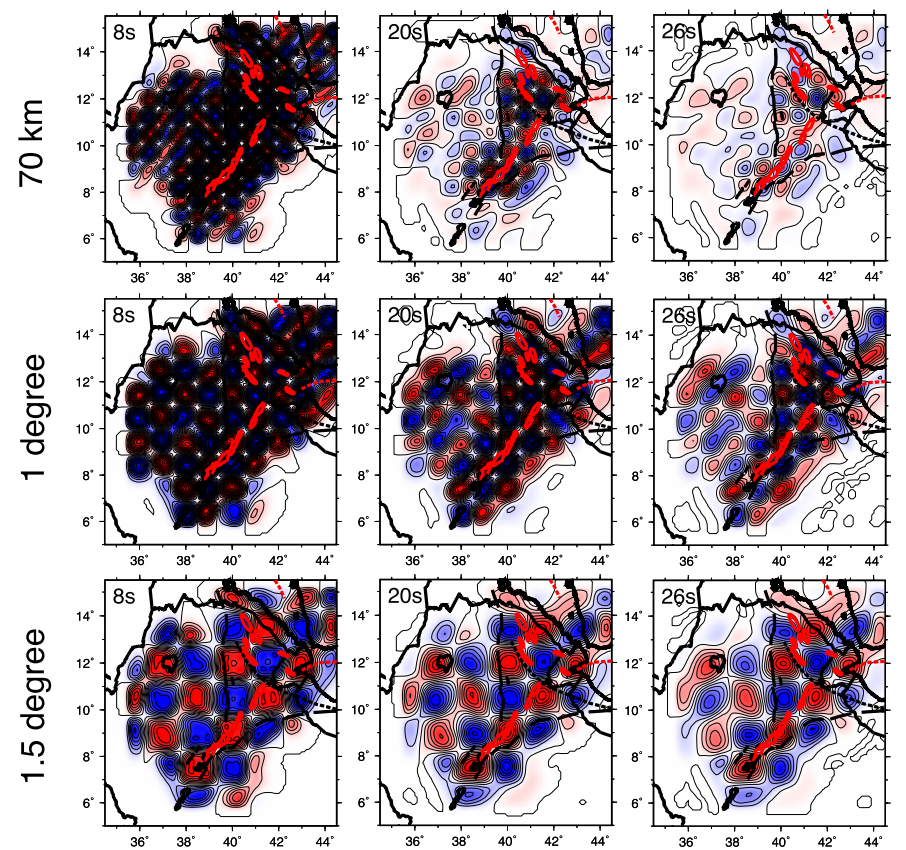

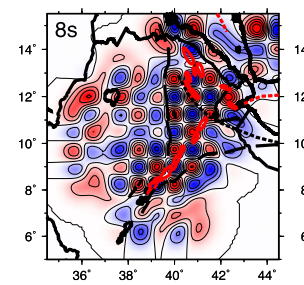

Love
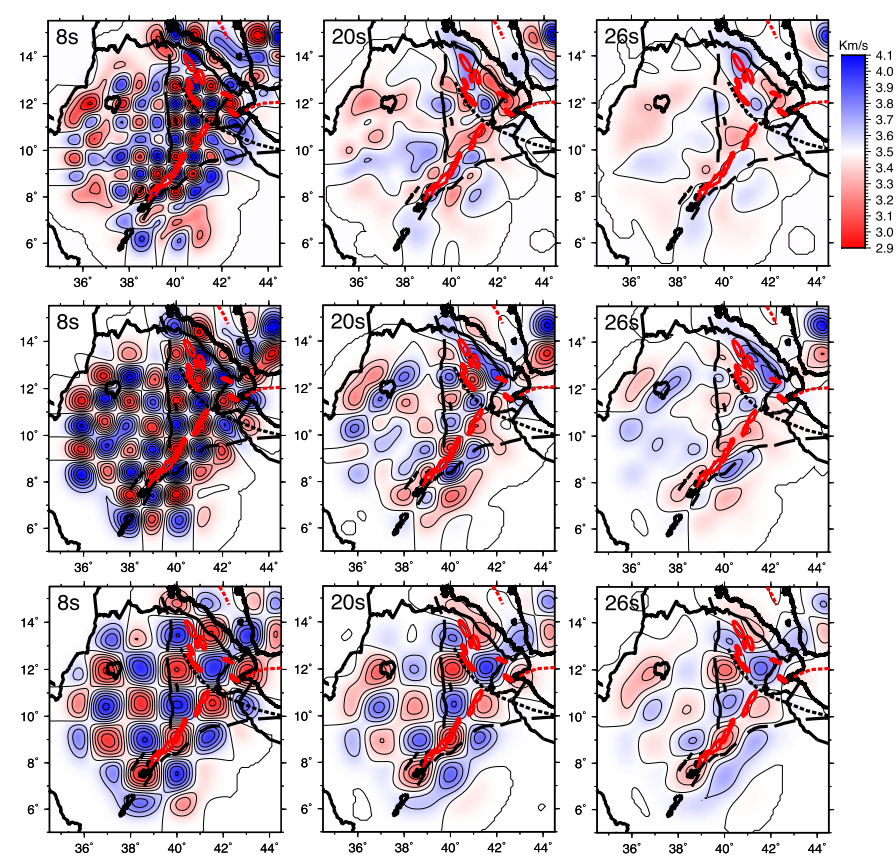

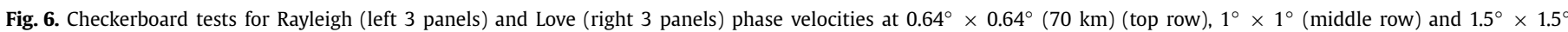

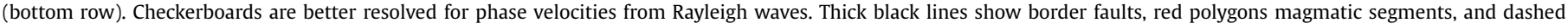
lines the Tendaho-Goba'ad discontinuity (TGD). 

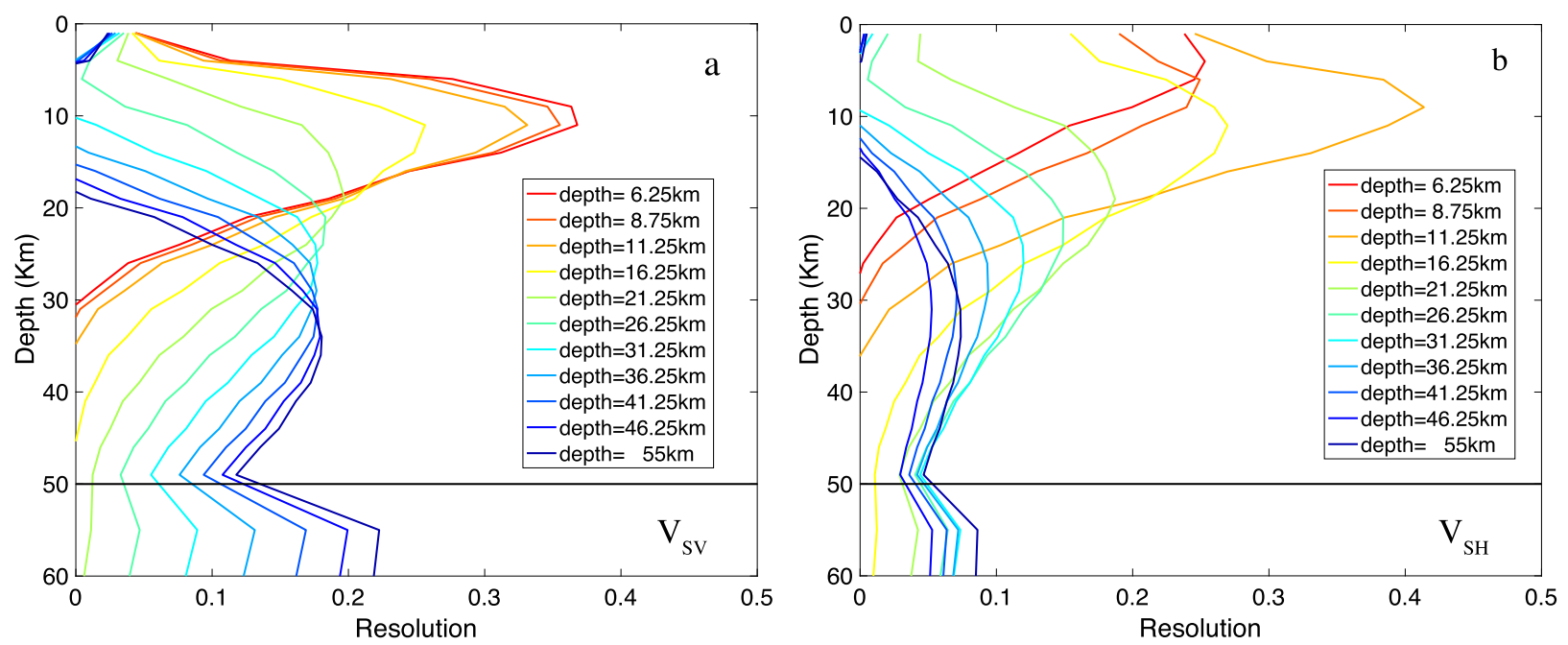

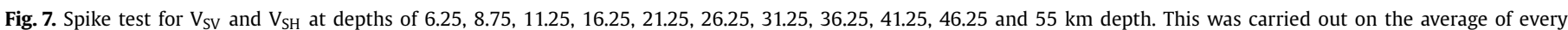

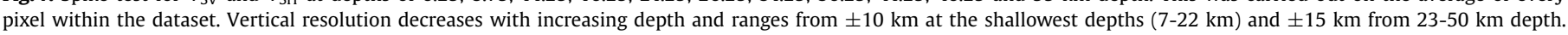

ternating thin compositional layers can account for the observed anisotropy and maximum apparent velocity discontinuity. This is done by modelling alternating thin layers, much smaller than a seismic wavelength, of low and high seismic velocity parallel to the Earth's surface with a vertical symmetry axis. Under these assumptions we use effective medium theory to calculate the radially anisotropic Christoffel Matrix from the distinct eigenvalues $\mathrm{V}_{\mathrm{SH}}$ and $\mathrm{V}_{\mathrm{SV}}$ (Backus, 1962) where

$L=\frac{1}{\frac{d_{1}}{\mu_{1}}+\frac{d_{2}}{\mu_{2}}} \quad$ and $\quad N=\mu_{1} d_{1}+\mu_{2} d_{2}$

$d_{1}$ and $d_{2}$ are the proportions of each layer (e.g. $d_{1}=d_{2}=0.5$, for layering with $50 \%$ granite and $50 \%$ rhyolite), and $\mu_{1}$ and $\mu_{2}$ are the shear moduli for the 2 alternating layers. Then

$V_{S H}=\sqrt{\frac{N}{\rho}}$

and

$V_{S V}=\sqrt{\frac{L}{\rho}}$

as discussed above.

Our models for $\mathrm{V}_{\mathrm{SV}}$ and $\mathrm{V}_{\mathrm{SH}}$ can be used to infer the shear moduli for the two layers and to assess whether melt is required in the crust. Specifically, if the required elastic moduli are too small to be explained by crystalline rocks, then melt is likely present. We assume the density of the medium is given by the weighted average of the respective layer thickness, $\rho=\rho_{1} d_{1}+\rho_{2} d_{2}$, where for the felsic layer we assigned a density of $2790 \mathrm{kgm}^{-3}\left(\rho_{1}\right)$ and $3000 \mathrm{kgm}^{-3}$ for the mafic intrusions $\left(\rho_{2}\right)$ from the gravity study of Cornwell et al. (2006). Substituting this expression for density and our observed $\mathrm{V}_{\mathrm{SV}}$ and $\mathrm{V}_{\mathrm{SH}}$ into the effective medium expressions for $\mathrm{N}$ and $\mathrm{L}$ results in the following expressions:

$$
\begin{aligned}
\mu_{2}= & \frac{\rho}{\left(2 * d_{2}\right)} *\left(\left(\mathrm{~V}_{\mathrm{SH}}^{2}-\mathrm{V}_{\mathrm{SV}}^{2}\right)+\left(2 * d_{2} * \mathrm{~V}_{\mathrm{SV}}^{2}\right)\right. \\
& \left.+\sqrt{\left(\mathrm{V}_{\mathrm{SH}}^{2}-\mathrm{V}_{\mathrm{SV}}^{2}\right) *\left(\left(\mathrm{~V}_{\mathrm{SH}}^{2}-\mathrm{V}_{\mathrm{SV}}^{2}\right)+4 * d_{2} * d_{1} * \mathrm{~V}_{\mathrm{SV}}^{2}\right)}\right) \\
\mu_{1}= & \frac{\left(\mathrm{V}_{\mathrm{SH}}^{2} * \rho-\left(d_{2} * \mu_{2}\right)\right)}{d_{1}}
\end{aligned}
$$

which provide expressions for $\mu_{1}$ and $\mu_{2}$ for a given choice of $d_{1}$ and $\mathrm{d}_{2}$ provided radial anisotropy is positive. We specified $\mu_{1}$ as the shear modulus of the felsic continental rock, and $\mu_{2}$ as the shear modulus of a solidified mafic intrusion, allowing both to be free parameters. For our observed $V_{S H}$ and $V_{S V}$ in Afar, the MER and the Ethiopian Plateau, we calculated the required value of $\mu_{1}$ and $\mu_{2}$ at different fractions of $d_{2}$ from $0-1$, where $d_{2}=1$ represents a crust of $100 \%$ mafic intrusions and $d_{1}=0$. This allows us to explore possible compositional combinations and whether melt is required, by comparing the shear moduli required to expected values for solid rocks.

\section{Results}

\subsection{1-D dispersion curves and shear velocity model}

Average phase and shear velocities and shear velocities for the region are shown in Fig. 3. The Love phase velocities range from 3.48-3.87 $\pm 0.03 \mathrm{~km} / \mathrm{s}$, while Rayleigh waves range from 3.21-3.56 $\mathrm{km} / \mathrm{s}$ for 9-26 s (Fig. 3c). Phase velocity of Love waves is greater than Rayleigh waves at all periods. The subsequent inversion for the best fit anisotropic 1-D model (using the isotropic model as the starting model) shows that both $\mathrm{V}_{\mathrm{SV}}$ and $\mathrm{V}_{\mathrm{SH}}$ (blue and black, respectively in Fig. 3a) have a broadly similar shape to the starting model, with $\mathrm{V}_{\mathrm{SV}}$ ranging from $2.97-4.21 \pm 0.02 \mathrm{~km} / \mathrm{s}$ and $\mathrm{V}_{\mathrm{SH}}$ moderately higher, ranging from $3.05-4.22 \pm 0.02 \mathrm{~km} / \mathrm{s}$ from $5-60$ $\mathrm{km}$ depth. Deeper than $30 \mathrm{~km}, \mathrm{~V}_{\mathrm{SV}}$ is not significantly different from $\mathrm{V}_{\mathrm{SH}}$. Therefore, radial anisotropy is not required to explain the data at these depths (Fig. 3a), which may reflect either real earth structure or the decreasing sensitivity of Love waves at $>30$ $\mathrm{km}$ depth. Between 5 and $30 \mathrm{~km}$ depth, $\mathrm{V}_{\mathrm{SH}}>\mathrm{V}_{\mathrm{SV}}$ and outside the 95\% confidence limits for the model parameters, requiring a maximum $\delta \mathrm{V}$ of $6.5 \%$ anisotropy. Furthermore, anisotropy is strongest in the upper $15 \mathrm{~km}$ and is weaker from 16-30 km depth, which are relatively-well resolved depth ranges based on the formal resolution matrix of the inversion.

\subsection{2-D phase velocities}

The phase velocity maps for Love and Rayleigh waves show broadly consistent structures (Fig. 4).

Average Love wave phase velocities range from 3.35-4.05 \pm $0.03 \mathrm{~km} / \mathrm{s}$ at $10-25 \mathrm{~s}$, while Rayleigh waves range from 2.95-3.78 $\pm 0.03 \mathrm{~km} / \mathrm{s}$ for the same period range. A low velocity anomaly 
is observed within the MER and beneath the eastern part of the Ethiopian Plateau, in both the Rayleigh and Love wave maps. The low velocity beneath the rift is centred west of the rift axis straddling the rift flank at periods longer than $20 \mathrm{~s}$, for both Love and Rayleigh phase velocities (3.10-3.45 $\pm 0.03 \mathrm{~km} / \mathrm{s}$ Rayleigh and $3.45-3.80 \pm 0.03 \mathrm{~km} / \mathrm{s}$ Love phase velocities). Furthermore, there is a low velocity anomaly visible in the Rayleigh phase velocities that extends along the MER from $6-8^{\circ} \mathrm{N}$, whereas Love waves have relatively high velocities at $15-20 \mathrm{~s}$ at $38^{\circ} \mathrm{E} 8^{\circ} \mathrm{N}$ (Love phase velocity 3.70-3.85 $\pm 0.04 \mathrm{~km} / \mathrm{s}$ vs. Rayleigh phase velocity 3.45-3.70 $\pm 0.03 \mathrm{~km} / \mathrm{s}$ ) (Fig. 4). Although this $1^{\circ}$ high velocity anomaly is at the limit of our lateral resolution at $20 \mathrm{~s}$. The Love waves show low velocities beneath Lake Tana $(3.45 \pm 0.05 \mathrm{~km} / \mathrm{s})$ which move progressively southeast with increasing period, in contrast to Rayleigh waves which stay focussed southeast of Lake Tana. Beneath the Erta Ale magmatic segment (EAMS), velocities are high for Rayleigh waves $(3.60 \pm 0.03 \mathrm{~km} / \mathrm{s}$ for all periods) but are low for Love waves where velocities are $3.75-3.85 \pm 0.03 \mathrm{~km} / \mathrm{s}$ at periods longer than $20 \mathrm{~s}$. The velocities beneath the EAMS are offset to the southwest which is likely due to limited station coverage in the north, with velocities averaged from the EAMS to Eritrea, in contrast to the south, where stations distribution is more concentrated. We speculate that with additional station coverage northeast of the EAMS, the low Love wave velocities could extend beneath the segment.

\subsection{Shear velocity $\left(V_{S V}\right)$}

The vertically polarised shear velocity maps are laterally heterogeneous, with velocities varying from $3.05-4.10 \pm 0.03 \mathrm{~km} / \mathrm{s}$ from 5-30 km depth (Fig. 5). The lowest velocities are beneath the MER and the eastern part of the Ethiopian Plateau (southeast of Lake Tana and west of the border fault), with minimum velocities of $3.15-3.60 \pm 0.04 \mathrm{~km} / \mathrm{s}$ (Fig. 5a-b). From 5-15 km depth the low velocities beneath the MER and Ethiopian Plateau are disparate and isolated (Fig. 5a), whereas from 16-30 km depth, the low velocities are continuous and broadly connected at the scale of our resolution (Fig. 5b). The highest velocities are beneath northern Afar at the EAMS from 5-30 km depth (minimum velocities of 3.53-3.90 $\pm 0.03 \mathrm{~km} / \mathrm{s}$ ) (Fig. 5a-b). We also observe high velocities beneath the western part of the Ethiopian Plateau (west of $37^{\circ} \mathrm{E}$ ) at 5-30 $\mathrm{km}$ (velocities of 3.50-4.10 $\pm 0.05 \mathrm{~km} / \mathrm{s}$ ) (Fig. 5a-b). Velocities are higher along the rift going northwards from the MER to Afar, with velocities at the Tendaho Goba-ad Discontinuity (dashed line Fig. 5, location where the MER transitions to Afar) ranging from $3.40 \pm$ $0.03 \mathrm{~km} / \mathrm{s}$ at $5-15 \mathrm{~km}$ depth, increasing to $3.70 \pm 0.03 \mathrm{~km} / \mathrm{s}$ at $16-30 \mathrm{~km}$ depth.

\subsection{Radial anisotropy}

Radial anisotropy $(\delta \mathrm{V})$, varies from -1 to $6.5 \pm 0.5 \%$ (Fig. $5 \mathrm{c}-\mathrm{d}$ ). The radial anisotropy is strongest in the upper crust $(\sim 2.5 \pm 0.5 \%$ at 5-15 km depth), becoming weaker at lower crustal depths $(\sim 1.5$ $\pm 0.5 \% 16-30 \mathrm{~km}$ depth), suggesting $\mathrm{V}_{\mathrm{SH}}>\mathrm{V}_{\mathrm{SV}}$ for most of the region (Fig. 5c-d). The main areas of horizontally aligned anisotropy are located where we observe the lowest shear velocity within the MER ( 2.5 to $6.0 \pm 0.5 \%)$ and off-rift beneath the Ethiopian Plateau, and along the western border fault $\left(39.5^{\circ} \mathrm{E}\right.$ Longitude, $10.5-12.5^{\circ} \mathrm{N}$ Latitude) ( 2.5 to $6.5 \pm 0.5 \%$ ). The strength of radial anisotropy decreases towards areas at more advanced rifting, dropping from values larger than $4.0 \pm 0.5 \%$ in the MER to $2.5 \pm 0.5 \%$ in Afar at 5-15 km depth. Within Afar there are areas where $\mathrm{V}_{\mathrm{SV}}>\mathrm{V}_{\mathrm{SH}}$, with the most significant (and above our threshold of $\pm 0.5 \%$ ) near the EAMS. Radial anisotropy in the EAMS is observed as $-1.0 \pm 0.5 \%$ from 5-30 km depth.
Table 1

Table for parameters used for the effective medium calculations with columns 1 and 2 extracted from Fig. 5 and the Intrusion percentage for Afar are from Eagles et al. (2002); Hammond et al. (2011) and Maguire et al. (2006), the MER, Daniels et al. (2014), the Ethiopian Plateau, Daniels et al. (2014).

\begin{tabular}{llll}
\hline & $\begin{array}{l}\text { Observed Velocity } \mathrm{V}_{\mathrm{SV}} \\
(\mathrm{km} / \mathrm{s})\end{array}$ & $\begin{array}{l}\text { Observed Anisotropy } \delta \mathrm{V} \\
(\%)\end{array}$ & $\begin{array}{l}\text { Intrusion } \\
(\%)\end{array}$ \\
\hline Afar & 3.43 & 1.98 & 50 \\
MER & 3.21 & 4.94 & 25 \\
Plateau & 3.29 & 5.94 & 20 \\
\hline
\end{tabular}

\subsection{Effective medium calculations - thin compositional layers}

We present further investigations of constraints on anisotropy by comparing the previously described effective medium predictions with our results at 3 locations: Central Afar, the MER and the Ethiopian Plateau. We took an average value for $\mathrm{V}_{\mathrm{SV}}$ and $\delta \mathrm{V}$ for each area, from 5-15 km depth (Fig. 5 and Table 1). These values were used to determine the shear moduli of the effective medium layers, $\mu_{1}$ and $\mu_{2}$ using equations (12) and (13) for the range of layer proportions. We then plotted the expected ranges for a granitic felsic crust (27.4-40 GPa) and a gabbroic mafic intrusion (40-60 GPa) (Hacker and Abers, 2004; Ji et al., 2010) (Fig. 8). Furthermore, we plot geologically inferred proportions of mafic intrusions in the crust as dashed coloured lines for each area, and use these as guidance to whether the proportion of our layers map within the bounds of the expected mafic intrusions. The geologically inferred proportions were calculated in other studies from the discrepancy between observed crustal thickness and predicted crustal thickness from rift stretching factor. For Afar, the proportion of intrusions is estimated as 50\% (Eagles et al., 2002; Hammond et al., 2011; Maguire et al., 2006), 25\% in the MER (Daniels et al., 2014), and 20\% for the Ethiopian Plateau (Daniels et al., 2014). Error bounds are based on the maximum errors in our choice of $V_{S V}$ and $\delta V$ and we propagate these to get lower and upper bounds on our result. In places where the curve for $\mu_{1}$ is within the bounds for felsic rock, such as Afar (red), this suggests solidified intrusions can account for the observed anisotropy. In the MER and Ethiopian Plateau (blue and green respectively), where anisotropy is stronger than the background of $2 \%$, we observe $\mu_{1}$ is lower than the range for felsic rocks at the geologically inferred proportions. This suggests either the calculated proportions of mafic vs felsic rock are incorrect and/or we require a component of partial melt, with more melt required in the MER (Fig. 8). Extreme and unphysical $\mu$ would be required for small $d$ values (upper white portion of the plot), i.e., outside the predicted ranges for composition (shaded areas), in order to satisfy the imposed anisotropy from our observations.

\section{Discussion}

Typically velocity variations in the $\mathrm{V}_{\mathrm{SV}}$ maps from $5-30 \mathrm{~km}$ depth (Fig. 5a-b), can be attributed to changes in crustal thickness (e.g. Hammond et al., 2011; Ogden et al., 2019). In Afar and the northernmost MER, average velocities are higher due to thinning crust and higher velocity mantle contributing to the image (Chambers et al., in review). The $\mathrm{V}_{\mathrm{SV}}$ maps show several low velocity regions associated with the Ethiopian Plateau, MER and central Afar. As has been discussed in greater detail in previous work (e.g. Chambers et al., 2019; Kim et al., 2012; Chambers et al., in review), velocities are lower than expected for crystalline crust and likely require some amount of partial melt likely associated with ongoing melt emplacement both on and off-rift. Low velocities are observed to increase northwards along the rift and focus to the magmatic segments, suggesting melt focussing to the rift axis occurs with progressive rifting (Chambers et al., 2019). Beneath the 


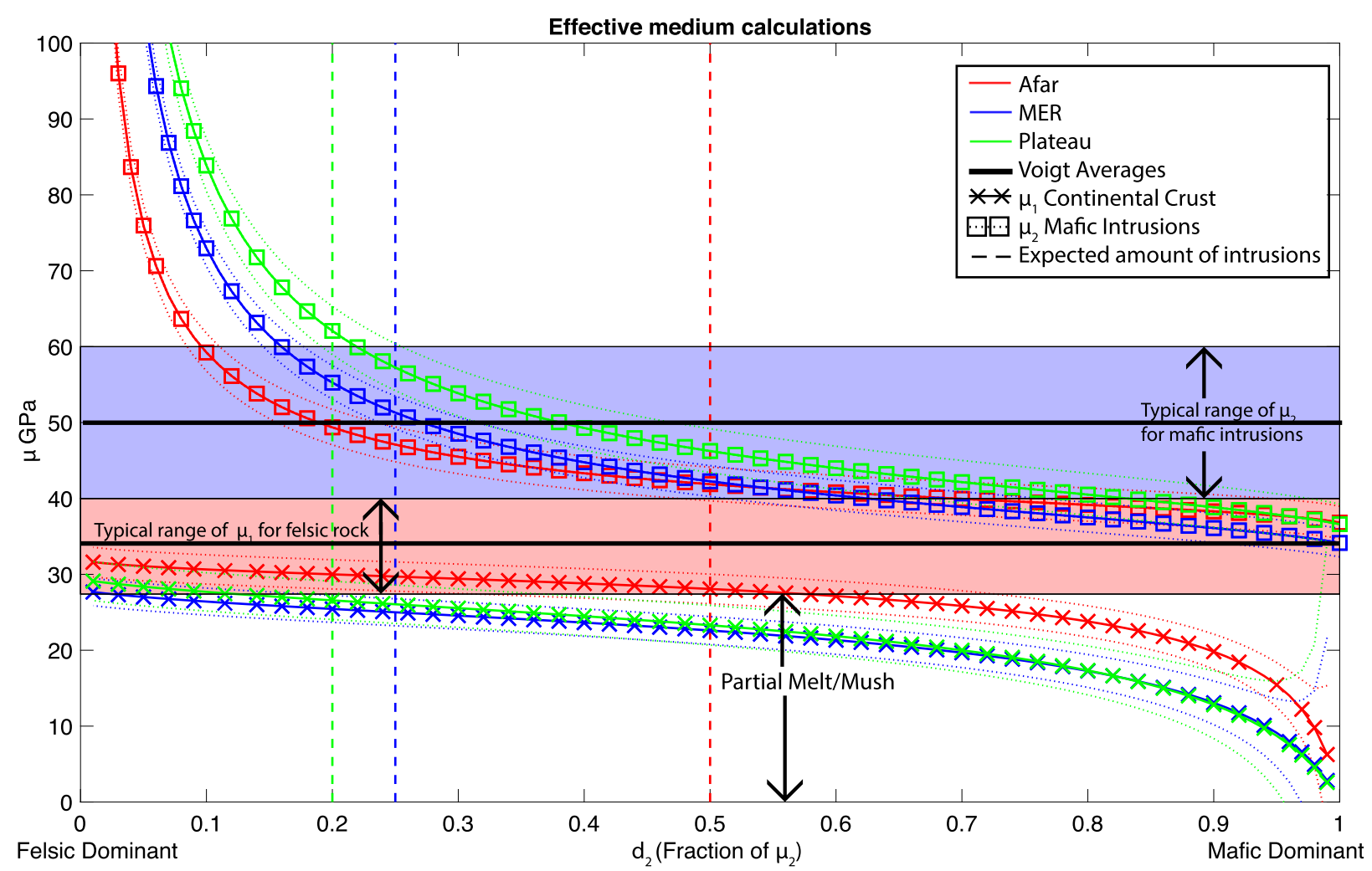

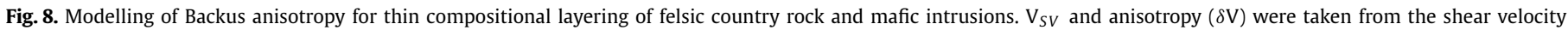

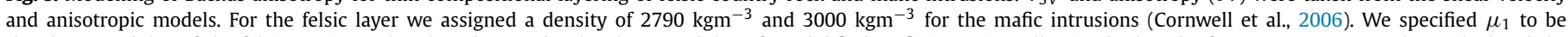

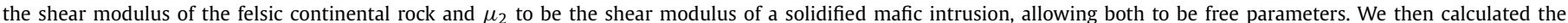

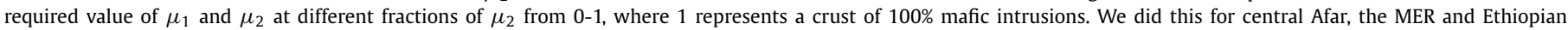

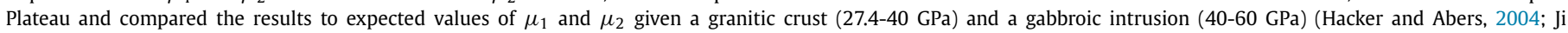

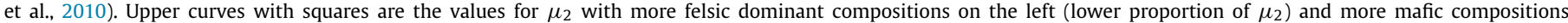

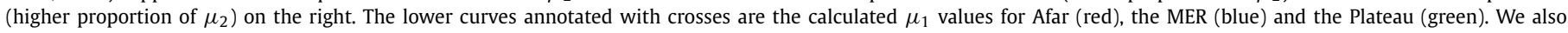

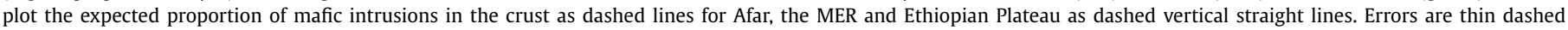
lines respective to each area and same colour based on the error in $V_{S V}$ and anisotropy $(\delta V)$.

Danakil depression, shear velocities are high which has previously been interpreted as more mafic rock compositions coupled with thinner crust (e.g. Chambers et al., 2019; Chambers et al., in review).

We can explain that, on average, $V_{S H}>V_{S V}$ is due to interlayering of felsic and mafic rock types as we demonstrated through the effective medium theory calculations. The dominant $\mathrm{V}_{\mathrm{SH}}>\mathrm{V}_{\mathrm{SV}}$ anisotropy suggests an inherently horizontally layered crustal structure within the nEAR. SPO of planar structures with contrasting elastic moduli can effectively create radial anisotropy, as demonstrated by Backus (1962). In extensional environments, crustal stretching can lead to horizontal layering and fabric development, in addition to fault systems, sedimentary deposition, magmatic intrusion/extrusion, and pre-existing layering of the continental crust can give rise to this type of anisotropy (Feng and Ritzwoller, 2019). Furthermore, although not relevant to our case, azimuthal anisotropy can be generated by crustal stretching causing Lattice Preferred Orientation, oriented parallel to the extension direction (Moschetti et al., 2007). Extension could account for some of the radial anisotropy, as has been observed in the Basin and Range where extension preferentially aligns seismically anisotropic crustal minerals (e.g. Moschetti et al., 2010), however we observe weaker radial anisotropy in areas of greater extension such as Afar when compared to the MER. Furthermore, while extension has been observed on the Ethiopian Plateau (Birhanu et al., 2016), these regions do not overlap with the areas of largest anisotropy. Given the limited relationship for extension with anisotropy and the presence of significant melt in this region, it is likely intru- sions are the dominant form of anisotropy, though we cannot rule out some influence from mineral alignment. In the uppermost crust, alternating layers of basalt flows and sediment have been observed (Bastow et al., 2010). However, below $5 \mathrm{~km}$ sediments are unlikely to be present and therefore not contribute to the anisotropy (Chorowicz, 2005). Similarly, alternating layers of continental crust or sedimentary layers within continental crust, do not have the density and shear modulus contrast to produce the largest observed variations in anisotropy (Kirkwood and Crampin, 1981). Magmatic intrusion within continental crust is an effective way to generate SPO anisotropy within the magmatically active rift (Kendall et al., 2006; Obrebski et al., 2010). Therefore, we interpret the background average $\mathrm{V}_{\mathrm{SH}}>\mathrm{V}_{\mathrm{SV}}$ of $2.5 \pm 0.5 \%(5-15 \mathrm{~km}$ depth) as indicating a layered felsic/mafic crustal structure reflecting widespread magmatic modification of the crust in the past $30 \mathrm{My}$, and also possibly from older fabric. In other words, the entire region is not a simple 2 layer felsic upper crust overlying a mafic lower crust (Rudnick and Fountain, 1995), but likely has widespread sill-like intrusions in the upper crust.

There are several strong $V_{S H}>V_{S V}$ with significantly low $V_{S V}$ anomalies across the region that cannot be explained by SPO of interlayered mafic and felsic rocks, but instead likely require melt. In particular, the strongest horizontally polarised anisotropy is found beneath the eastern part of the Ethiopian Plateau ( $\delta \mathrm{V}$ of 2.5 to 6.5 $\pm 0.5 \%$ ) close to the western border fault where there are steeply dipping faults at the surface. We expect $V_{S V}>V_{S H}$ in the vicinity of the faults, but this is not observed. We suggest surface wave radial anisotropy may not resolve small scale vertical features, the 
features do not contain large amounts of fluid, or that the vertical extent of these faults is limited to $<5 \mathrm{~km}$ (Holtzman and Kendall, 2010). Beneath the Ethiopian Plateau, we interpret the strong radial anisotropy as layered horizontal sills in the crust. The high values of radial anisotropy ( $\delta \mathrm{V}$ up to $6.5 \pm 0.5 \%$ Fig. $5 c-d$ ) are difficult to produce from solidified mafic/felsic rocks (Fig. 8), especially at the previously interpreted proportions of felsic/mafic material in the crust. However, for a small amount of partial melt (up to $2.7 \%$ ) and a reasonable $\mu$ for country rock, we can match our $\mathrm{V}_{\mathrm{SV}}$ and $\mathrm{V}_{\mathrm{SH}}$ (Fig. 8). Anisotropy is stronger in the $5-15 \mathrm{~km}$ depth slice suggesting melt is preferentially stored as sills in the mid-to-upper crust. Recent geophysical studies find highly conductive (Whaler and Hautot, 2006) and low velocity anomalies (Chambers et al., 2019) at mid crustal depths, as far north as Lake Tana, providing support for this interpretation. Geochemistry studies also find evidence for melt in sills beneath the Ethiopian Plateau (Rooney, 2017), which combined with significant geothermal activity (Keir et al., 2009) and high Vp/Vs ratios (>1.8) (Hammond et al., 2011) support melt.

The MER has significant radial anisotropy ( $\delta \mathrm{V}$ of 2.5 to $6 \pm$ $0.5 \%$ ) present beneath the full rift width, and effective medium calculations suggest this area requires partial melt. Anisotropy is stronger in the upper 5-15 km and weaker at 16-30 km depth, but shear velocity is low enough to require melt at all depths (3.55$3.75 \pm 0.03 \mathrm{~km} / \mathrm{s}$ ). We suggest melt is present at mid-to-lower crustal depths and is either more heterogeneous in shape and orientation or stored as a combination of dykes and sills, at a resolution too small for this study to determine. The strongest $\mathrm{V}_{\mathrm{SH}}>\mathrm{V}_{\mathrm{SV}}$ radial anisotropy is consistently in the $5-15 \mathrm{~km}$ depth slice, suggesting either the density structure of the crust or the state of stress is amenable to sill formation at present. Previous magnetotelluric studies find evidence for mid-to-upper crustal melt zones beneath volcanoes in the rift (Whaler and Hautot, 2006). However, seismic reflection studies find strong layered lower crustal reflectors (Maguire et al., 2006). The discrepancy potentially arises due to variations in imaging solidified sills as lower crustal intrusions vs. molten active intrusion in the surface waves (Kendall et al., 2006).

Beneath the EAMS, we observe $\mathrm{V}_{\mathrm{SV}}>\mathrm{V}_{\mathrm{SH}}(\delta \mathrm{V}$ down to $-1.0 \pm$ $0.5 \%$ ), indicating vertically oriented planar features which could be explained by dyke intrusion. The signal is clearly visible in the phase velocity maps (Fig. 4), where this is the only strong low velocity region in the Love wave phase velocity maps, but is within the background velocity in the Rayleigh wave maps at periods $>20$ s. Rayleigh waves, due to their sensitivity to $V_{S V}$, are less sensitive to melt in near vertical dykes, as the polarization is in the plane of the structure, resulting in higher observed velocities in areas of highly intruded mafic crust (Hammond, 2014). Our observations suggest aligned dykes and associated fractures extend to $15 \mathrm{~km}$ depth or more, as the anisotropic signature is visible in our $16-30 \mathrm{~km}$ depth average. The crust here is thinner $\sim 16 \mathrm{~km}$ (Hammond et al., 2011) so our depth averaging likely includes crust and mantle material in the shallowest average slice, making precise interpretation of whether it is due to intrusion through the crust or mantle difficult. Geodetic observations of northern Afar also show this region has experienced recent upper crustal dyking events (Moore et al., 2019).

Anisotropy becomes weaker along rift from $6 \pm 0.5 \%$ in the southern MER to $2 \pm 0.5 \%$ in the northern MER and $-1 \pm 0.5 \%$ in the EAMS. We also observe anisotropy beneath the full rift width in the south, which localises to the magmatic segments in the north. These observations can be interpreted either as a change from dominantly sill emplacement in the narrow MER to dyke emplacement in Afar, or a reduction in the volume of melt towards later stage rifting.
The surface waves presented here and previous shear-wave splitting studies find differences within the MER, with fast direction in shear-wave splitting studies consistent with vertically aligned fluid filled cracks observed at mid-to-upper crustal depths (Keir et al., 2011; Kendall et al., 2006), which are not imaged by surface waves (e.g. Bastow et al., 2010; Kendall et al., 2006). This is likely due to the varying sensitivities of the two methods. Given the relatively broad lateral sensitivity $(\sim 100 \mathrm{~km})$ of the surface waves used here, we expect our method will struggle to resolve localised anisotropy over $<50 \mathrm{~km}$ lateral scales observed in the shear wave splitting (Kendall et al., 2006). Furthermore, local shear wave splitting results may be most sensitive to structure $<5 \mathrm{~km}$ deep, where our result is poorly resolved. We suggest melt is stored both as stacked sills and oriented melt pockets with a higher concentration of dykes in Afar, and more sills in the MER.

Our observations are in good agreement with geochemical studies which suggest melt has a primarily mantle origin and propagates as dykes in Afar, whereas more crustal assimilation and evolved magmas are observed in the MER where melt is thought to be stored as sills (Hutchison et al., 2018). In northern Afar, anisotropy studies find similar results that suggest dykes are the most efficient melt transport mechanism (Hammond, 2014; Hammond et al., 2014; Keir et al., 2011). At mantle depths beneath the EAMS, we observe little anisotropy suggesting melt retains no preferential alignment, in agreement with Hammond et al. (2014). Active source profiles beneath the Ethiopian Plateau and the MER find evidence for horizontal layering and lower crustal intrusions which decrease towards Afar (Maguire et al., 2006). Our results suggest layering resulting in anisotropy extends to $30 \mathrm{~km}$, but no deeper, perhaps indicating either a lower volume of lower crustal intrusions observed at $>30 \mathrm{~km}$ depth or the layers have no dominant orientation.

The presence of stacked sills in the crust of a narrow rift, and dykes at a wider rift, are observed in other rifting/mid-ocean ridge regions and volcanic regions. At mid-ocean ridges evidence for horizontal layering consistent with low-to-mid crustal sill emplacement is observed in the NoMelt experiment (Russell et al., 2019) and significant lower crustal intrusions as stacked sills in the Baikal rift (Thybo and Nielsen, 2009). At some mid-ocean ridges, purely laminar structures are proposed (e.g. Shito et al., 2015), however, these results require strong radial but weak azimuthal anisotropy, in contrast to the nEAR. In regions of upwelling (e.g. East Pacific Rise), $V_{S V}>V_{S H}$ is observed (Toomey et al., 2007) and interpreted as vertical flow of melt, similarly to what we observe within the EAMS. Strong crustal radial anisotropy has been observed beneath large calderas in arc settings, continental hotspots (e.g. Yellowstone) and the basin and range, interpreted as the locus of voluminous silicic magmatism forming large sill complexes, supporting the concept of long-term incremental evolution of magma bodies (Jiang et al., 2018). Similarly, in magmatic regions with thickened continental crust, strong lower crustal radial anisotropy has been interpreted as deep sills that occur in thickened regions which may accelerate the processing of primary basalts to continental compositions (Harmon and Rychert, 2015). Away from the caldera and along hot spot trends, anisotropy weakens suggesting seismic contrasts fade with crystallisation (Jiang et al., 2018).

Melt ascends due to variations in buoyancy between melt and the crust. Melt will stop when it reaches neutral buoyancy in the crust or where the elastic and tectonic stresses prevent melt from rising further (Roberts, 1970). In the EAR, we expect the density structure and stress regime to change as the relatively thick continental crust and narrow rift in the MER transitions to the thinner crust and broader rift zone of Afar, based on numerical models of rift evolution (Maccaferri et al., 2014). Specifically, in a narrow rift, stress changes caused by topography and crustal thickness variations favour sill intrusion. As the rift widens, stress changes are 


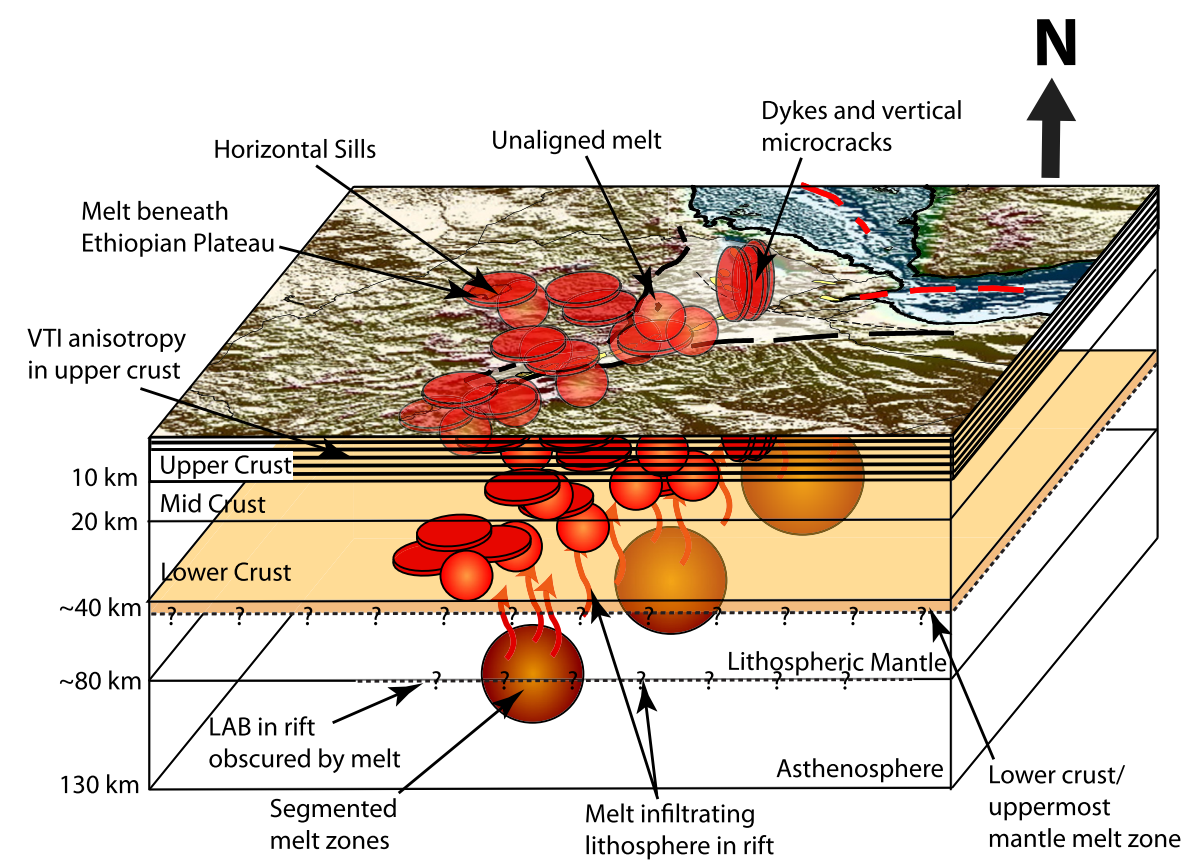

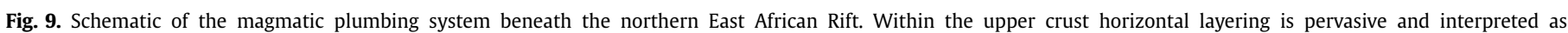

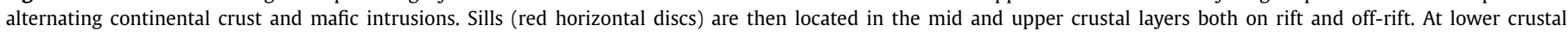

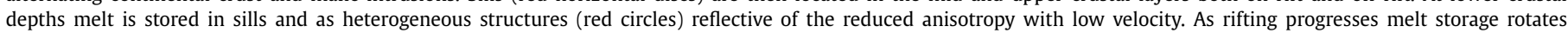

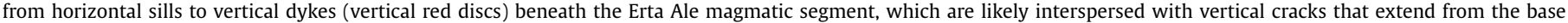

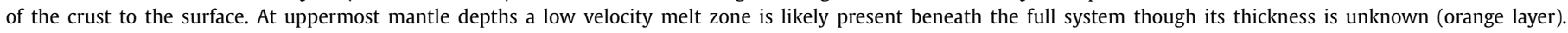

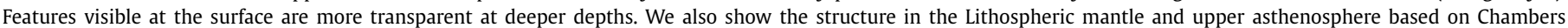

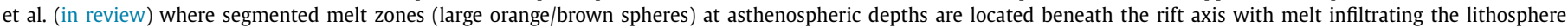
(red arrows) and obscuring the lithosphere asthenosphere boundary at 60-80 km depth (dashed line with ? at $\sim 80 \mathrm{~km}$ depth).

less important, favouring dyking (Maccaferri et al., 2014). Stacked sill complexes in narrow rifts are consistent with more recent conceptual models of incremental magma reservoirs (Cashman and Giordano, 2014) and variations in the geochemistry of erupted rocks (Hutchison et al., 2018). We summarise our interpretation of anisotropy and melt storage in the crust in Fig. 9. The new knowledge of the structure and depth of melt storage is important for our understanding of the evolution of rifting in regions with variable crustal thickness and topography.

\section{Conclusions}

We determine radial anisotropy in the nEAR using surface waves from Love and Rayleigh waves from 9-26 s period, finding on average Love waves $0.40 \pm 0.03 \mathrm{~km} / \mathrm{s}$ higher than Rayleigh waves. In the crust we require an anisotropic model from 5-30 $\mathrm{km}$. Deeper than $30 \mathrm{~km}$ radial anisotropy is not required. We observe $V_{S H}>V_{S V}$ across most of our study, suggesting an inherently layered crust. Effective medium calculations indicate thin compositional layering of felsic crust and mafic intrusions can account for up to $4 \%$ of the horizontally polarised anisotropy, including in Afar. However, to reconcile larger anisotropy, where we observe the lowest velocities and largest anisotropy (up to $6.5 \pm 0.5 \%$ ), partial melt is required, stored as stacked sills. Our model suggests the largest anisotropy and lowest velocities beneath both the MER and Ethiopian Plateau can be interpreted as stacked sills in the upper to mid crust, both on and off-rift. In the southern MER radial anisotropy is horizontally aligned, getting progressively weaker towards areas at more advanced rifting, suggesting stacked sills in the upper-to-mid crust become less dominant with progressive rifting. Similarly, anisotropy is weaker at lower crustal depths (16-30 km) but velocities are low enough to require melt, suggesting melt is stored as a combination of sills and isotropic bodies. As the rift widens and crust thins, anisotropy reduces which could indicate a change in melt storage from dominantly horizontally aligned (sills), to vertical (dykes) and unaligned melt. Beneath the EAMS we observe $\mathrm{V}_{\mathrm{SV}}>\mathrm{V}_{\mathrm{SH}}$, which we interpret as vertically aligned micro-cracks and dykes, providing conduits for vertical flow of melt to feed recent eruptions. Our results suggest rift width and crustal thickness provide controls on how melt is stored in the crust. Narrower rifts with thicker crust favour sill formation both on and off-rift, while in more advanced broader rift regions with thinner crust, magma driven extension at the rift axis occurs mainly by dyking.

\section{CRediT authorship contribution statement}

Emma L. Chambers: Conceptualization, Data curation, Formal analysis, Investigation, Methodology, Software, Validation, Visualization, Writing - original draft, Writing - review \& editing. Nicholas Harmon: Conceptualization, Formal analysis, Investigation, Methodology, Software, Supervision, Writing - original draft, Writing - review \& editing. Catherine A. Rychert: Conceptualization, Supervision, Writing - original draft, Writing - review \& editing. Derek Keir: Conceptualization, Investigation, Supervision, Writing - original draft, Writing - review \& editing.

\section{Declaration of competing interest}

The authors declare that they have no known competing financial interests or personal relationships that could have appeared to influence the work reported in this paper.

\section{Acknowledgements}

E.L.C is funded through NERC studentship NE/L002531/1. D.K. is supported by NERC grant NE/L013932 and by MIUR through PRIN grant 2017P9AT72. C.A.R. and N.H. acknowledge funding from 
the Natural Environment Research Council (NE/M003507/1 and $\mathrm{NE} / \mathrm{K} 010654 / 1$ ) and the European Research Council (GA 638665). All data needed to generate these models are freely available from the IRIS Data Management Center (IRISDMC; https://service.iris. edu/fdsnws/dataselect/1/). IRIS Data Services are funded through the Seismological Facilities for the Advancement of Geoscience and EarthScope (SAGE) Proposal of the National Science Foundation under Cooperative Agreement EAR-126168. We thank SEIS-UK for use of the instruments and their computing facilities. The facilities of SEIS-UK are supported by the Natural Environment Research Council (NERC) under agreement R8/H10/64.F. The final velocity and anisotropy model is available at https://doi.org/10.5258/SOTON/ D1689.

\section{Appendix A. Supplementary material}

Supplementary material related to this article can be found online at https://doi.org/10.1016/j.epsl.2021.117150.

\section{References}

Backus, G.E., 1962. Long-wave elastic anisotropy produced by horizontal layering. J. Geophys. Res. 67 (11), 4427-4440. https://doi.org/10.1029/jz067i011p04427.

Bastow, I.D., Pilidou, S., Kendall, J.-M., Stuart, G.W., 2010. Melt-induced seismic anisotropy and magma assisted rifting in Ethiopia: evidence from surface waves. Geochem. Geophys. Geosyst. 11 (6), 1-19. https://doi.org/10.1029/ 2010GC003036.

Bensen, G.D., Ritzwoller, M.H., Barmin, M.P., Levshin, A.L., Lin, F.-C., Moschetti, M.P., et al., 2007. Processing seismic ambient noise data to obtain reliable broad-band surface wave dispersion measurements. Geophys. J. Int. 169 (3), 1239-1260. https://doi.org/10.1111/j.1365-246X.2007.03374.X.

Birhanu, Y., Bendick, R., Fisseha, S., Lewi, E., Floyd, M., King, R., Reilinger, R., 2016. GPS constraints on broad scale extension in the Ethiopian Highlands and Main Ethiopian Rift. Geophys. Res. Lett. 43 (13), 6844-6851. https://doi.org/10.1002/ 2016 GL069890.

Cashman, K.V., Giordano, G., 2014. Calderas and magma reservoirs. J. Volcanol. Geotherm. Res. 288, 28-45. https://doi.org/10.1016/j.jvolgeores.2014.09.007.

Chambers, E.L., Harmon, N., Keir, D., Rychert, C.A., 2019. Using ambient noise to image the northern East African Rift. Geochem. Geophys. Geosyst. 20, 2091-2109. https://doi.org/10.1029/2018GC008129.

Chambers, E.L., Harmon, N., Rychert, C.A., Gallacher, R.J., Keir, D., in review. Imaging the seismic velocity structure of the crust and upper mantle in the northern East African Rift using Rayleigh wave tomography. Geophys. J. Int. https://doi. org/10.31223/X5XK6X.

Chorowicz, J., 2005. The East African rift system. J. Afr. Earth Sci. 43, 379-410. https://doi.org/10.1016/j.jafrearsci.2005.07.019.

Cornwell, D.G., Mackenzie, G.D., England, R.W., Maguire, P.K.H., Asfaw, L., Oluma, B., 2006. Northern Main Ethiopian Rift crustal structure from new high-precision gravity data. Geol. Soc. (Lond.) Spec. Publ. 259 (1), 307-321. https://doi.org/10. 1144/GSL.SP.2006.259.01.23.

Daniels, K.A., Bastow, I.D., Keir, D., Sparks, R.S.J., Menand, T., 2014. Thermal models of dyke intrusion during development of continent-ocean transition. Earth Planet. Sci. Lett. 385, 145-153. https://doi.org/10.1016/j.epsl.2013.09.018.

Eagles, G., Gloaguen, R., Ebinger, C.J., 2002. Kinematics of the Danakil microplate. Earth Planet. Sci. Lett. 203, 607-620.

Feng, L., Ritzwoller, M.H., 2019. A 3-D shear velocity model of the crust and uppermost mantle beneath Alaska including apparent radial anisotropy. J. Geophys. Res., Solid Earth 124 (10), 10468-10497. https://doi.org/10.1029/2019JB018122.

Forsyth, D.W., Li, A., 2005. Array analysis of two-dimensional variations in surface wave phase velocity and azimuthal anisotropy in the presence of multipathing interference. Seismic Earth: Array Anal. Broadband Seism., 81-97. https://doi. org/10.1029/157GM06.

Hacker, B.R., Abers, G.A., 2004. Subduction Factory 3: an Excel worksheet and macro for calculating the densities, seismic wave speeds, and $\mathrm{H} 2 \mathrm{O}$ contents of minerals and rocks at pressure and temperature. Geochem. Geophys. Geosyst. 5, Q01005. https://doi.org/10.1029/2003GC000614.

Hammond, J.O.S., 2014. Constraining melt geometries beneath the Afar Depression, Ethiopia from teleseismic receiver functions: the anisotropic H-k stacking technique. Geochem. Geophys. Geosyst. 15 (4), 1316-1322. https://doi.org/10.1002/ 2013 GC005186.

Hammond, J.O.S., Kendall, J.-M., Stuart, G.W., Keir, D., Ebinger, C.J., Ayele, A., Belachew, M., 2011. The nature of the crust beneath the Afar triple junction: evidence from receiver functions. Geochem. Geophys. Geosyst. 12 (12), 1-24. https://doi.org/10.1029/2011GC003738.

Hammond, J.O.S., Kendall, J.-M., Wookey, J., Stuart, G.W., Keir, D., Ayele, A., 2014. Differentiating flow, melt, or fossil seismic anisotropy beneath
Ethiopia. Geochem. Geophys. Geosyst. 15, 1878-1894. https://doi.org/10.1002/ 2013GC005185.Received.

Harmon, N., Forsyth, D.W., Webb, S.C., 2007. Using ambient seismic noise to determine short-period phase velocities and shallow shear velocities in young oceanic lithosphere. Bull. Seismol. Soc. Am. 97 (6), 2009-2023. https://doi.org/ 10.1785/0120070050.

Harmon, N., Rychert, C.A., 2015. Seismic imaging of deep crustal melt sills beneath Costa Rica suggests a method for the formation of the Archean continental crust. Earth Planet. Sci. Lett. 430, 140-148. https://doi.org/10.1016/j.epsl.2015.07.062.

Holtzman, B.K., Kendall, J.-M., 2010. Organized melt, seismic anisotropy, and plate boundary lubrication. Geochem. Geophys. Geosyst. 11 (12), 1-29. https://doi. org/10.1029/2010GC003296.

Hutchison, W., Mather, T.A., Pyle, D.M., Boyce, A.J., Gleeson, M.L.M., Yirgu, G., et al., 2018. The evolution of magma during continental rifting: new constraints from the isotopic and trace element signatures of silicic magmas from Ethiopian volcanoes. Earth Planet. Sci. Lett. 489, 203-218. https://doi.org/10.1016/j.epsl.2018. 02.027.

Ji, S., Sun, S., Wang, Q., Marcotte, D., 2010. Lamé parameters of common rocks in the Earth's crust and upper mantle. J. Geophys. Res., Solid Earth 115 (6). https:// doi.org/10.1029/2009JB007134.

Jiang, C., Schmandt, B., Farrell, J., Lin, F.-C., Ward, K.M., 2018. Seismically anisotropic magma reservoirs underlying silicic calderas. Geology 46 (8), 727-730. https:// doi.org/10.1130/G45104.1.

Keir, D., Bastow, I.D., Whaler, K.A., Daly, E., Cornwell, D.G., Hautot, S., 2009. Lower crustal earthquakes near the Ethiopian rift induced by magmatic processes. Geochem. Geophys. Geosyst. 10 (6), 1-10. https://doi.org/10.1029/ 2009GC002382.

Keir, D., Belachew, M., Ebinger, C.J., Kendall, J.-M., Hammond, J.O.S., Stuart, G.W., et al., 2011. Mapping the evolving strain field during continental breakup from crustal anisotropy in the Afar Depression. Nat. Commun. 2, 285-287. https:// doi.org/10.1038/ncomms1287.

Kendall, J.-M., Pilidou, S., Keir, D., Bastow, I.D., Stuart, G.W., Ayele, A., 2006. Mantle upwellings, melt migration and the rifting of Africa: insights from seismic anisotropy. Geol. Soc. (Lond.) Spec. Publ. 259, 55-72.

Kim, S., Nyblade, A.A., Rhie, J., Baag, C.-E., Kang, T.-S., 2012. Crustal S-wave velocity structure of the Main Ethiopian Rift from ambient noise tomography. Geophys. J. Int. 191 (2), 865-878. https://doi.org/10.1111/j.1365-246X.2012.05664.x.

Kirkwood, S.C., Crampin, S., 1981. Surface-wave propagation in an ocean basin with an anisotropic upper mantle: observations of polarization anomalies. Geophys. J. R. Astron. Soc. 64 (2), 487-497. https://doi.org/10.1111/j.1365-246X. 1981.tb02678.x.

Landisman, M., Dziewonski, A., Satô, Y., 1969. Recent improvements in the analysis of surface wave observations. Geophys. J. R. Astron. Soc. 17, 369-403. https:// doi.org/10.4294/jpe1952.16.Special_1.

Lin, F.-C., Moschetti, M.P., Ritzwoller, M.H., 2008. Surface wave tomography of the western United States from ambient seismic noise: Rayleigh and Love wave phase velocity maps. Geophys. J. Int. 173 (1), 281-298. https://doi.org/10.1111/ j.1365-246X.2008.03720.x.

Maccaferri, F., Rivalta, E., Keir, D., Acocella, V., 2014. Off-rift volcanism in rift zones determined by crustal unloading. Nat. Geosci. 7 (4), 297-300. https://doi.org/10. 1038/ngeo2110.

Maguire, P.K.H., Keller, G.R., Klemperer, S.L., Mackenzie, G.D., Keranen, K.M., Harder, S., et al., 2006. Crustal structure of the northern Main Ethiopian Rift from the EAGLE controlled-source survey; a snapshot of incipient lithospheric break-up. Geol. Soc. (Lond.) Spec. Publ. 259 (1), 269-291. https://doi.org/10.1144/GSL.SP. 2006.259.01.21.

Montagner, J.P., Anderson, D.L., 1989. Constrained reference mantle model. Phys. Earth Planet. Inter. 58 (2-3), 205-227. https://doi.org/10.1016/0031-9201(89) 90055-1.

Moore, C., Wright, T.J., Hooper, A., Biggs, J., 2019. The 2017 eruption of Erta 'Ale Volcano, Ethiopia: insights into the shallow axial plumbing system of an incipient mid-ocean ridge. Geochem. Geophys. Geosyst. 20, 1-17. https://doi.org/10.1029/ 2019GC008692.

Moschetti, M.P., Ritzwoller, M.H., Lin, F.-C., Yang, Y., 2010. Seismic evidence for widespread western-US deep-crustal deformation caused by extension. Nature 464 (7290), 885-889. https://doi.org/10.1038/nature08951.

Moschetti, M.P., Ritzwoller, M.H., Shapiro, N.M., 2007. Surface wave tomography of the western United States from ambient seismic noise: Rayleigh wave group velocity maps. Geochem. Geophys. Geosyst. 8 (8), 1-10. https://doi.org/10.1029/ 2007 GC001655.

Obrebski, M., Kiselev, S., Vinnik, L., Montagner, J.P., 2010. Anisotropic stratification beneath Africa from joint inversion of SKS and P receiver functions. J. Geophys. Res., Solid Earth 115 (9), 1-15. https://doi.org/10.1029/2009JB006923.

Ogden, C.S., Bastow, I.D., Gilligan, A., Rondenay, S., 2019. A reappraisal of the H- $\kappa$ stacking technique: implications for global crustal structure. Geophys. J. Int. 219, 1491-1513. https://doi.org/10.1093/gji/ggz364.

Roberts, J.L., 1970. The intrusion of magma into brittle rocks. J. Geol. 2, 380.

Rooney, T.O., 2017. The Cenozoic magmatism of East-Africa: Part I - flood basalts and pulsed magmatism. Lithos 286-287, 264-301. https://doi.org/10.1016/j. lithos.2017.05.014. 
Rudnick, R.L., Fountain, D.M., 1995. Nature and composition of the continental crust: a lower-crustal perspective. Rev. Geophys. 33 (3), 267-309. https://doi.org/10. 1029/95rg01302.

Russell, J.B., Gaherty, J.B., Lin, P.Y.P., Lizarralde, D., Collins, J.A., Hirth, G., Evans, R.L. 2019. High-resolution constraints on Pacific upper mantle petrofabric inferred from surface-wave anisotropy. J. Geophys. Res., Solid Earth 124 (1), 631-657. https://doi.org/10.1029/2018JB016598.

Saito, M., 1988. DISPER80: a subroutine package for the calculation of seismic normal-mode solutions. In: Doornbos, D.J. (Ed.), Seismological Algorithms: Computational Methods and Computer Programs. Academic Press, pp. 293-319.

Shito, A., Suetsugu, D., Furumura, T., 2015. Evolution of the oceanic lithosphere inferred from Po/So waves traveling in the Philippine Sea Plate. J. Geophys. Res., Solid Earth 120, 5238-5248. https://doi.org/10.1002/2015JB012608.Received.

Tarantola, A., Valette, B., 1982. Generalized nonlinear inverse problems solved using the least squares criterion. Rev. Geophys. 20 (2), 219-232. https://doi.org/10. 1029/RG020i002p00219.
Thybo, H., Nielsen, C.A., 2009. Magma-compensated crustal thinning in continental rift zones. Nature 457 (7231), 873-876. https://doi.org/10.1038/nature07688.

Toomey, D.R., Jousselin, D., Dunn, R.A., Wilcock, W.S.D., Detrick, R.S., 2007. Skew of mantle upwelling beneath the East Pacific Rise governs segmentation. Nature 446 (7134), 409-414. https://doi.org/10.1038/nature05679.

Whaler, K.A., Hautot, S., 2006. The electrical resistivity structure of the crust beneath the northern Main Ethiopian Rift. Geol. Soc. (Lond.) Spec. Publ. 259, 293-305.

Wolfenden, E., Ebinger, C.J., Yirgu, G., Renne, P.R., Kelley, S.P., 2005. Evolution of a volcanic rifted margin: Southern Red Sea, Ethiopia. Bull. Geol. Soc. Am. 117 (7-8), 846-864. https://doi.org/10.1130/B25516.1.

Yang, Y., Forsyth, D.W., 2006. Regional tomographic inversion of the amplitude and phase of Rayleigh waves with 2-D sensitivity kernels. Geophys. J. Int. 166 (3), 1148-1160. https://doi.org/10.1109/TIM.2006.876410.

Zhou, Y., Dahlen, F.A., Nolet, G., 2004. Three-dimensional sensitivity kernels for surface wave observables. Geophys. J. Int. 158 (1), 142-168. https://doi.org/10.1111/ j.1365-246X.2004.02324.x. 